03

\title{
Запись и визуализация волоконных решеток показателя преломления с наклонными штрихами
}

\author{
(ㄱ К.А. Коннов, Е.А. Фролов, А.И. Грибаев, В.В. Захаров, А.А. Михнева, В.А. Новикова, С.В. Варжель \\ Университет ИТМО, \\ 197101 Санкт-Петербург, Россия \\ e-mail: fralik95@list.ru
}

Поступила в редакцию 31.12.2017 г.

В окончательной редакции 19.03.2018 г.

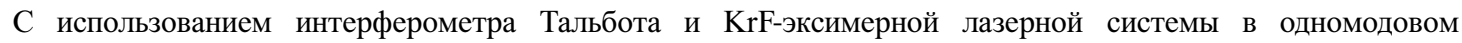
изотропном оптическом волокне с повышенной фоторефрактивностью записаны наклонные волоконные брэгговские решетки с различными углами наклона. Изучены их спектры. С помощью конфокального лазерного сканирующего люминесцентного микроскопа получены изображения решеток в проходящем свете. Экспериментально проверена расчетная зависимость угла наклона решетки, записываемой в интерферометре Тальбота, от угла между штрихами интерференционной картины, создаваемой в интерферометре, и поперечным сечением оптического волокна.

DOI: $10.21883 /$ OS.2018.07.46266.2-18

\section{Введение}

В связи с быстрым развитием технологий изготовления волоконно-оптических устройств решетки Брэгга нашли свое применение в качестве пассивных оптических элементов, получивших распространение в областях оптических телекоммуникаций, волоконных лазеров и сенсорных систем. Такие структуры характеризуются полностью волоконным исполнением, малыми размерами, защищенностью от воздействия электромагнитных полей, долговечностью, стабильностью, низкими вносимыми потерями и гибкой спектральной передаточной характеристикой [1-4].

Первые исследования волоконных дифракционных структур были сосредоточены на формировании эффективных и стабильных во времени стандартных решеток Брэгга, что предъявляло требования к увеличению фоторефрактивности оптических волокон $(\mathrm{OB})$ и устранению несовершенств в технологиях их изготовления. Однако уже в 1990 г. на конференции Оптических Волоконных Коммуникаций (OFC) Г. Мельц и др. впервые представили модель модового взаимодействия на наклонной волоконной брэгговской решетке (НВБР) [5]. Было показано, что взаимодействие мод на фазовых дифракционных решетках может быть в некоторой степени усилено с помощью введения угла между штрихами решетки и поперечным сечением ОВ.

В отличие от стандартных волоконных брэгговских решеток (ВБР) штрихи НВБР имеют определенный угол наклона относительно поперечного сечения $\mathrm{OB}$, в связи с чем возникает более сложное модовое взаимодействие. Вследствие наличия угла наклона перекачка света происходит из сердцевины световода в подмножество большого числа мод, которые могут распространяться в оболочке ОВ.

Одно из преимуществ НВБР состоит в том, что они могут связывать направляемые моды на опреде- ленных длинах волн с модами, распространяющимися в обоих направлениях. Направление распространения будет зависеть от угла наклона решетки, что подробнее описано далее. Эта особенность позволяет использовать НВБР при изготовлении сглаживающего эрбиевого усилителя [6], оптического анализатора спектра [7], фильтра ввода-вывода [8]. Другая особенность НВБР они чувствительны к показателю преломления внешней среды, что позволяет использовать их при изготовлении рефрактометров [9-11] и измерителей концентрации $[12,13]$. НВБР, имеющие относительно большой угол наклона, обладают высокой чувствительностью к состоянию поляризации проходящего света. Таким образом, они могут быть использованы в качестве поляриметра [14-16], датчика кручения [17], поляризационнозависимого эквалайзера [18].

Для оптимизации записи НВБР в используемом в работе оптическом волокне требуется точно знать зависимость угла наклона решетки, записываемой в интерферометре Тальбота, от угла между штрихами интерференционной картины, создаваемой в интерферометре, и поперечным сечением оптического волокна. Для достижения поставленной цели были решены следующие задачи: записаны НВБР с различными углами наклона, проведена визуализация образцов НВБР на оптическом микроскопе и проанализированы полученные изображения; проведено сопоставление экспериментальных данных и расчетной зависимости угла наклона решетки от угла между штрихами интерференционной картины и поперечным сечением оптического волокна.

\section{Наклонные волоконные решетки показателя преломления}

Как и стандартные ВБР, НВБР обладают периодической модуляцией показателя преломления вдоль оси ОВ, 


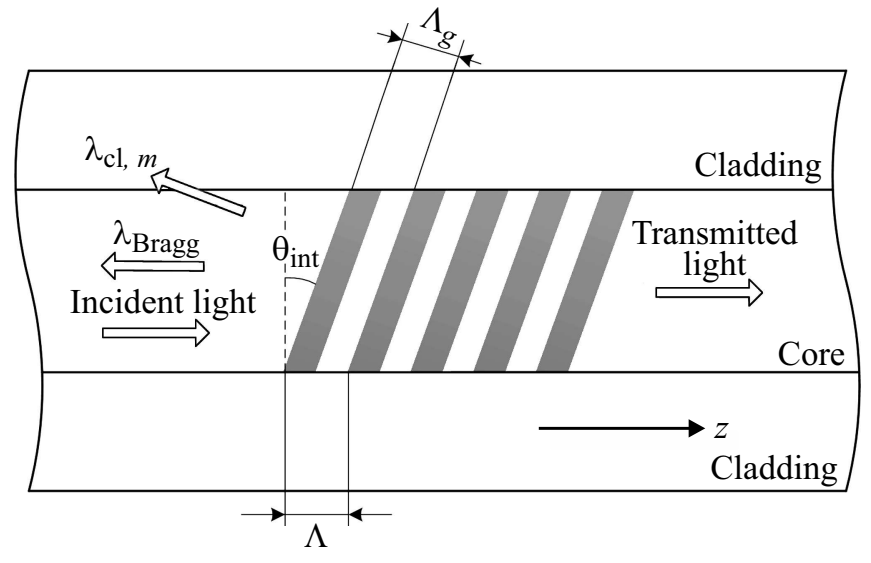

Рис. 1. Структурная схема НВБР.

однако отличаются от ВБР тем, что имеют определенный угол между штрихами решетки и поперечным сечением световода, что приводит к возникновению более сложного модового взаимодействия, как показано на рис. 1.

Вследствие наличия угла наклона кроме взаимодействия мод сердцевины, распространяющихся в прямом и обратном направлениях, которое наблюдается на стандартных ВБР, в НВБР возникает взаимодействие мод сердцевины и оболочки, которое включает взаимодействие моды сердцевины, распространяющейся в прямом направлении, и моды оболочки, распространяющейся в том же и противоположном направлениях. Соответственно спектр пропускания НВБР имеет множественные резонансные пики, которые отсутствуют в спектре отражения из-за быстрого затухания оболочечных мод. Направление распространения оболочечных мод будет зависеть от угла наклона решетки $\theta_{\text {int }}$ (рис. 1). Если $\theta_{\text {int }}<45^{\circ}$, то мода сердцевины будет взаимодействовать с модой оболочки, распространяющейся в противоположном направлении, а если $\theta_{\text {int }}>45^{\circ}$, то в том же направлении.

Для связанных мод коэффициент фазового рассогласования $\Delta \beta$ равен

$$
\Delta \beta=\beta_{i} \pm \beta_{d}-\frac{2 \pi}{\Lambda_{g}} N \cos \theta_{\mathrm{int}},
$$

где $\beta_{i}$ и $\beta_{d}$ - постоянные распространения для падающей и дифрагированной моды соответственно, $\Lambda_{g}-$ период решетки, $\theta_{\text {int }}$ - угол наклона решетки, а $N$ целое число. Стоит отметить, что знак „ \pm “ описывает случай, когда мода распространяется в направлении ,Ф“' $z$ (рис. 1).

Когда условие согласования фаз выполняется, $\Delta \beta=0$, то выражение (1) будет иметь вид

$$
\beta_{i} \pm \beta_{d}=\frac{2 \pi}{\Lambda_{g}} N \cos \theta_{\text {int }}
$$

Если и $\beta_{i}$, и $\beta_{d}$ имеют одинаковые знаки, то фаза будет согласована для мод, распространяющихся в противопо- ложных направлениях; если они имеют противоположные знаки, то взаимодействуют моды, распространяющиеся в одном и том же направлении. В большинстве случаев доминирует дифракция первого порядка, поэтому $N$ предполагается равным единице $[19,20]$.

Для количественного описания передаточной характеристики НВБР необходимо получить выражение, которое определяет длину волны резонанса моды оболочки. Резонансная длина волны, зависящая от параметров решетки, в НВБР может быть получена путем решения уравнений модового взаимодействия, однако куда более удобно решить эту задачу, пользуясь аналогией между резонансными условиями для ВБР и НВБР. Для стандартных ВБР резонансная длина волны, удовлетворяющая условию Брэгга, может быть описана как

$$
\lambda_{\text {Bragg }}=\left(n_{\text {core }, i}^{\mathrm{eff}}+n_{\text {core }, d}^{\mathrm{eff}}\right) \Lambda_{g},
$$

где $n_{\mathrm{core}, i}^{\mathrm{eff}}, n_{\mathrm{core}, d}^{\mathrm{eff}}-$ эффективные показатели преломления для падающей и дифрагированной моды сердцевины ОВ соответственно. Под брэгговским резонансом понимается взаимодействие между модами сердцевины, распространяющимися в прямом и обратном направлениях. В свою очередь, для НВБР из-за появления угла наклона $\theta_{\text {int }}$ период решетки вдоль оси ОВ может быть пересчитан как

$$
\Lambda=\frac{\Lambda_{g}}{\cos \theta_{\text {int }}} .
$$

C учетом угла наклона $\theta_{\text {int }}$ условие брэгговского резонанса для НВБР принимает вид

$$
\lambda_{\mathrm{Bragg}}=\left(n_{\mathrm{core}, i}^{\mathrm{eff}}+n_{\mathrm{core}, d}^{\mathrm{eff}}\right) \frac{\Lambda_{g}}{\cos \theta_{\mathrm{int}}} .
$$

В связи с тем, что НВБР имеет определенный угол наклона к оси $\mathrm{OB}$, часть света, распространяющегося по сердцевине, при взаимодействии с решеткой будет перетекать в моды оболочки, распространяющиеся в прямом и противоположном направлениях. Тогда уравнение для резонансной длины волны для мод оболочки примет вид

$$
\lambda_{\mathrm{cl}, m}=\left(n_{\mathrm{core}}^{\mathrm{eff}} \pm n_{\mathrm{cl}, m}^{\mathrm{eff}}\right) \frac{\Lambda_{g}}{\cos \theta_{\mathrm{int}}},
$$

где $n_{\mathrm{cl}, m}^{\mathrm{eff}}-$ эффективный показатель преломления $m$-й моды оболочки.

В уравнении (6) знаки „,+“ и ,-““ описывают ситуации, когда мода распространяется в направлениях $-z$ и $+z$ (рис. 1) соответственно для случаев перекачки моды сердцевины в моду оболочки, распространяющуюся в обратном направлении и в прямом [20].

\section{Схема записи наклонных волоконных решеток}

Для данной работы был использован интерферометрический метод записи, который описан в работе [21]. Такой способ предоставляет возможность изменения 


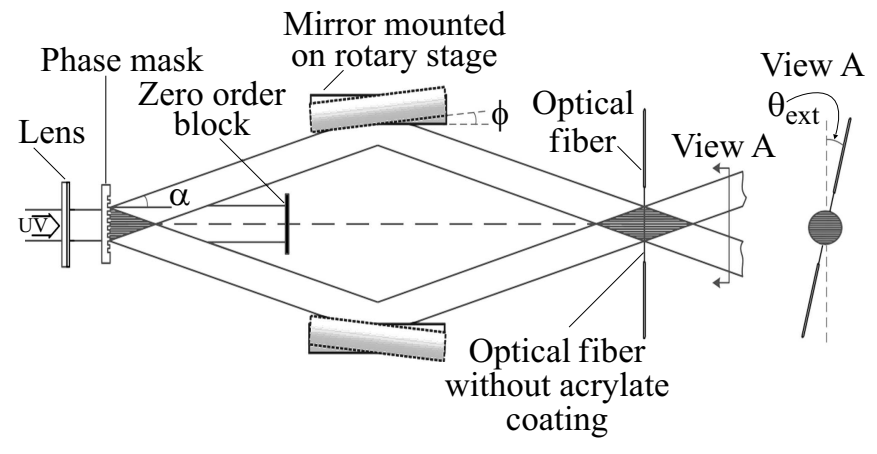

Рис. 2. Схема интерферометра Тальбота.

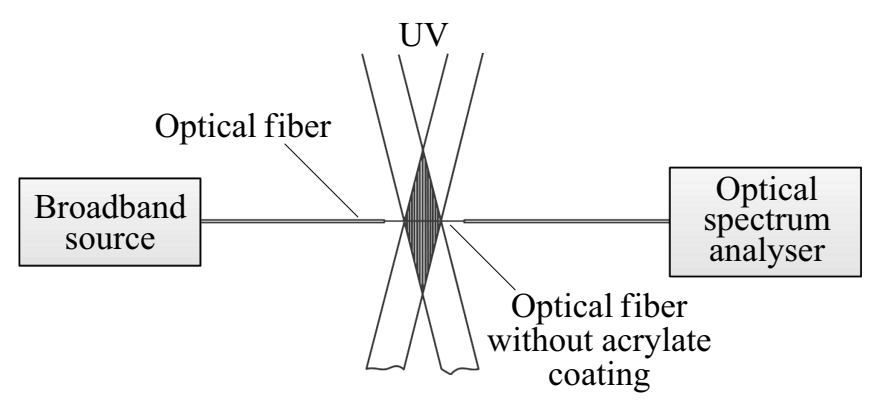

Рис. 3. Экспериментальная схема для наблюдения спектра пропускания.

периода интерференционной картины в широком диапазоне (путем поворота зеркал на угол $\phi$ (рис. 2)), что позволяет записывать ВБР с различным периодом, при этом используется только одна фазовая маска для амплитудного разделения лазерного пучка. Также данный способ можно использовать для записи решеток показателя преломления в процессе вытяжки ОВ в связи с отсутствием непосредственного контакта фазовой маски и световода, который имеет место в случае записи методом фазовой маски. Функциональная схема интерферометра Тальбота, оптимизированная для записи НВБР, представлена на рис. 2, где $\alpha-$ угол дифракции 1-го порядка.

Схема была доработана путем установки поворотного держателя ОВ. Изменяя угол поворота ОВ $\theta_{\text {ext }}$ (внешний угол наклона) относительно интерференционной картины, можно получать НВБР с различными углами наклона $\theta_{\text {int }}$.

\section{Экспериментальные результаты}

Для экспериментов использовалось одномодовое изотропное ОВ (диаметр кварцевой оболочки $125 \mu \mathrm{m}$ ) с повышенной фоторефрактивностью производства НИТИОМ ВНЦ „ГОИ им. С.И. Вавилова“. Повышение фоторефрактивности волоконного световода производилось путем увеличения концентрации диоксида германия до $12 \mathrm{~mol} \%$ на этапе формирования заготовки (в стандартном телекоммуникационном ОВ $-3 \mathrm{~mol} . \%)$ и по- следующей водородной обработки. Условия проведения водородной обработки ОВ те же, что и в работе [22].

После удаления защитной акрилатной оболочки волоконный световод устанавливается в поворотный держатель. Для того чтобы установить положение ОВ, при котором его ось была бы перпендикулярна штрихам интерференционной картины, необходимо записывать решетки, поворачивая ОВ с достаточно малым шагом (в настоящей работе данный шаг составлял $0.2^{\circ}$ ), при этом отслеживая в спектре отражения изменение положения пика, соответствующего длине волны Брэгга. При достижении $\lambda_{\text {Bragg }}$ минимального значения такое положение ОВ принимается за $0^{\circ}$.

Для записи одной НВБР ОВ облучалось в течение $1 \mathrm{~min}$ с частотой $10 \mathrm{~Hz}$, при этом плотность энергии на поверхности волоконного световода составляла
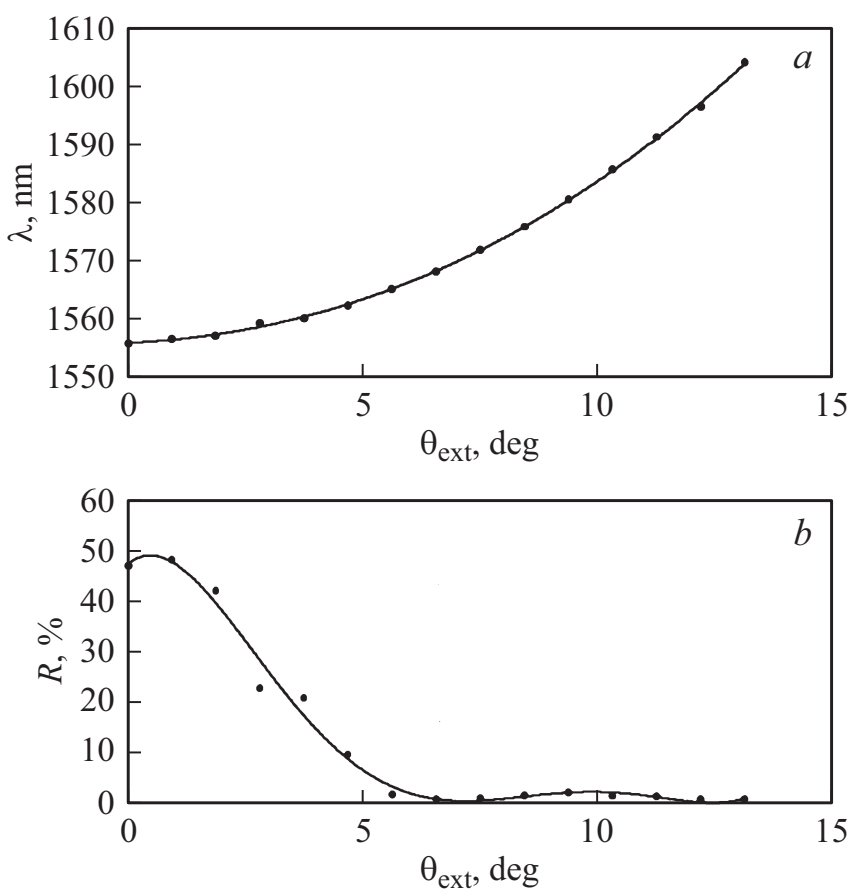

Рис. 4. Зависимости длины волны Брэгга $\lambda_{\text {Bragg }}(a)$ и коэффициента отражения $R(b)$ решетки от внешнего угла наклона $\theta_{\text {ext }}$.
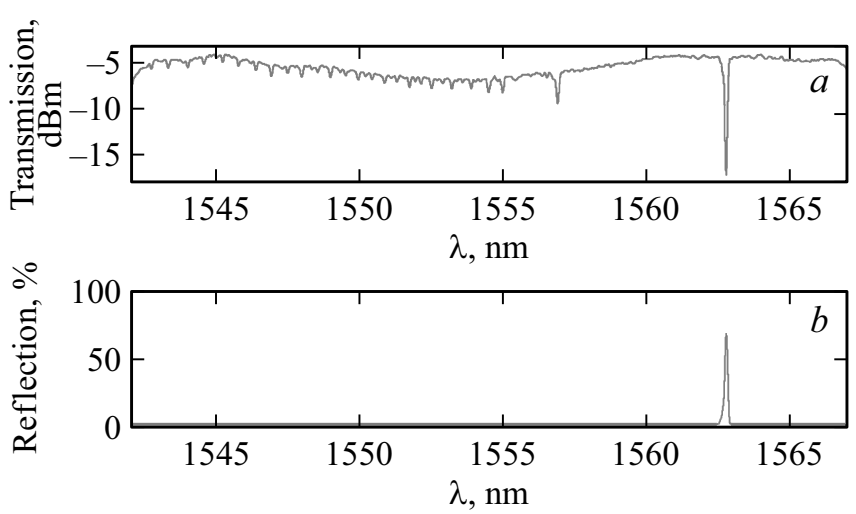

Рис. 5. Спектры пропускания $(a)$ и отражения $(b)$ НВБР с внешним углом наклона $4^{\circ}$. 

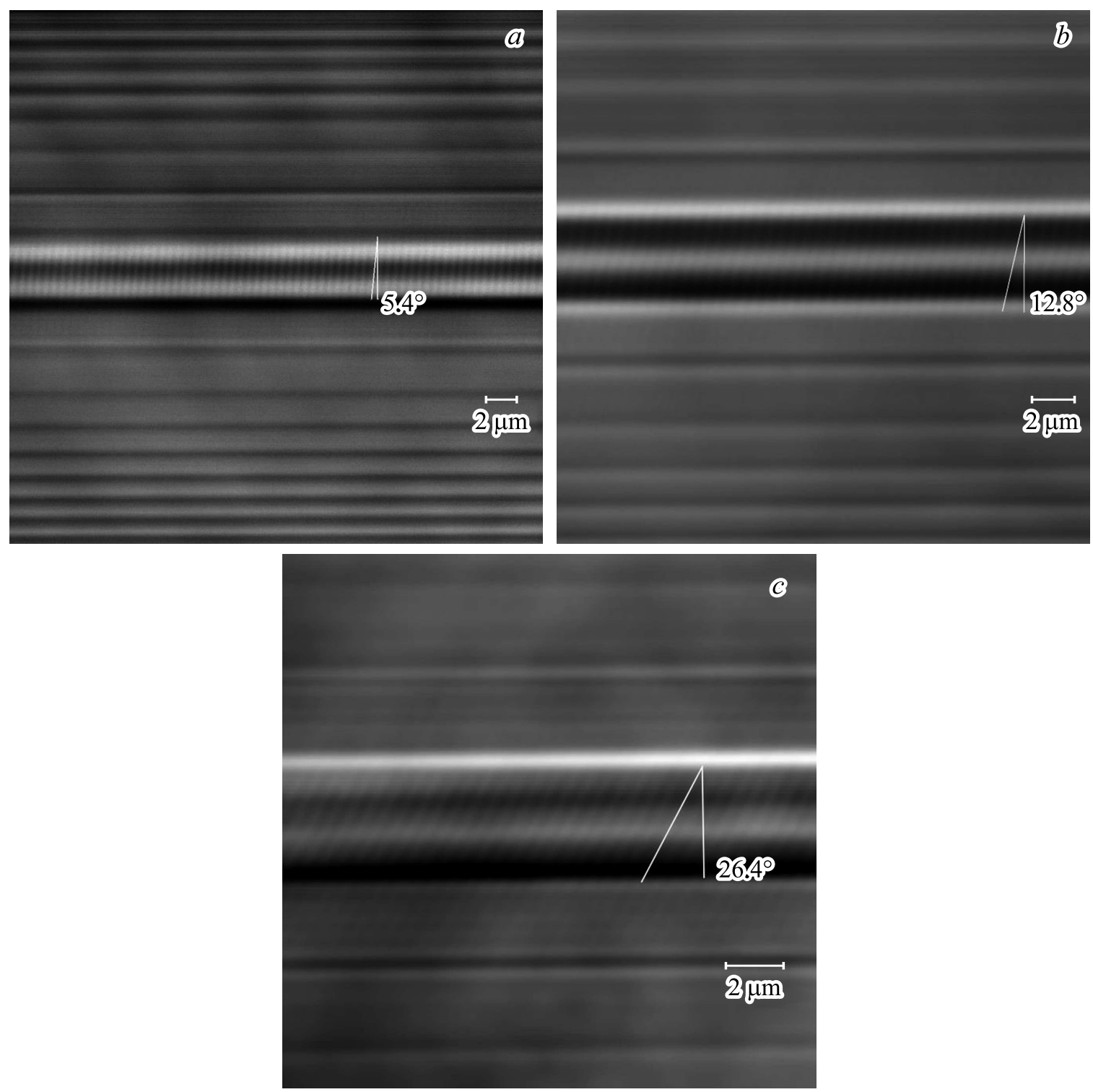

Рис. 6. Изображения НВБР с внешними углами наклона $4^{\circ}(a), 10^{\circ}(b)$ и $20^{\circ}(c)$, полученные на конфокальном сканирующем микроскопе.

$220 \mathrm{~mJ} / \mathrm{cm}^{2}$. Для того чтобы была возможность отслеживать не только изменение пика, соответствующего длине волны Брэгга, но и множество пиков, соответствующих взаимодействию моды сердцевины и оболочечных мод, регистрировался спектр пропускания с помощью схемы, представленной на рис. 3. Спектр наблюдался на оптическом спектроанализаторе Yokogawa AQ6370C с диапазоном измерений $600-1700 \mathrm{~nm}$ и разрешающей способностью $20 \mathrm{pm}$.

В ходе работы были получены образцы НВБР, записанные с различными внешними углами наклона $\theta_{\text {ext. }}$. C увеличением $\theta_{\text {ext }}$ значение длины волны Брэгга $\lambda_{\text {Bragg }}$ также увеличивается, но при этом уменьшается дифракционная эффективность брэгговского резонанса решетки, о чем свидетельствуют зависимости, представленные на рис. 4. Данные зависимости построены для исполь- зуемого в работе изотропного оптического волокна без водородной обработки. Зависимость, представленная на рис. 4, $a$, может быть использована при записи ВБР методом фазовой маски, одним из недостатков которого является фиксированное значение периода интерференционной картины, образующейся за фазовой маской. Таким образом, с помощью введения угла наклона $\theta_{\mathrm{ext}}$ можно подстраивать длину волны брэгговского резонанса индуцируемой решетки. Чем больше угол, тем меньше связь мод сердцевины, распространяющихся в прямом и обратном направлениях (рис. $4, b$ ), поэтому эффективно такую подстройку можно осуществлять только в области малых углов.

На рис. 5 представлены спектры пропускания $(a)$ и отражения $(b)$ НВБР с внешним углом наклона $4^{\circ}$, длина волны Брэгга в этом случае равна $\lambda_{\text {Bragg }}=1562.74 \mathrm{~nm}$. 


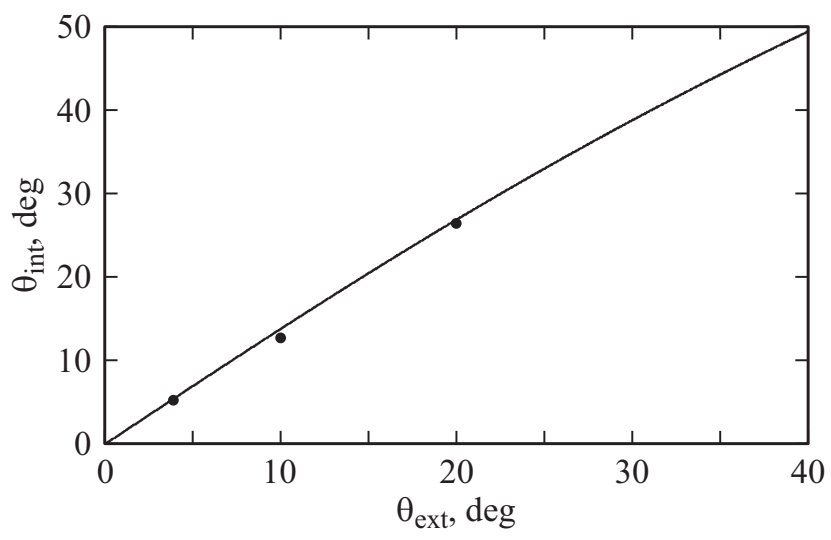

Рис. 7. Расчетная зависимость (сплошная линия) и экспериментальные значения (точки) угла наклона штрихов в НВБР $\theta_{\text {int }}$ от внешнего угла наклона $\theta_{\text {ext }}$.

НВБР индуцирована в изотропном оптическом волокне, подвергнутом водородной обработке.

\section{Визуализация наклонных волоконных решеток показателя преломления}

С помощью конфокального лазерного сканирующего микроскопа Zeiss LSM 710 в проходящем свете лазера с длиной волны $405 \mathrm{~nm}$ проведена визуализация НВБР с различными углами наклона. На рис. 6 представлены изображения НВБР с внешними углами наклона $4^{\circ}(a)$, $10^{\circ}(b)$ и $20^{\circ}(c)$. Изображения волоконных решеток получали методом светлого поля с иммерсионным объективом с апертурой 1.3. НВБР индуцированы в изотропном оптическом волокне, подвергнутом водородной обработке. Путем вращения ОВ относительно своей оси добивались того положения, при котором штрихи НВБР были перпендикулярны оси ОВ, после чего с помощью поворотного держателя ОВ вместе с решеткой поворачивали на $90^{\circ}$, что соответствовало максимальному углу наклона НВБР. Из рис. 6 видно, что внутренний угол наклона решетки $\theta_{\text {int }}$ отличается от внешнего $\theta_{\text {ext }}$ (угла между штрихами интерференционной картины и поперечным сечением ОВ). Связано это с тем, что при прохождении УФ излучения через ОВ возникает призматический эффект из-за его цилиндрической формы. Измеренные значения внутренних углов наклона решеток $\theta_{\text {int }}$ составляли $5.4^{\circ}, 12.8^{\circ}$ и $26.4^{\circ}$, соответствующие внешним углам наклона $\theta_{\text {ext }}=4^{\circ}, 10^{\circ}$ и $20^{\circ}$.

Полученные экспериментальные значения близки к теоретическим, рассчитанным по формуле (7) [20], о чем свидетельствуют данные, представленные на рис. 7:

$$
\theta_{\mathrm{int}}=\frac{\pi}{2}-\arctan \frac{1}{n \tan \theta_{\mathrm{ext}}},
$$

где $n$ - показатель преломления оболочки ОВ.

\section{Заключение}

НВБР представляет собой универсальное устройство для выборочного возбуждения определенных мод оболочки, посредством чего имеется возможность регистрировать изменение состояния окружающей среды, контролируя спектральный отклик решетки, что может быть реализовано в оптических датчиках. Так как реакция на внешнее изменение мод оболочки с различными эффективными показателями преломления и моды сердцевины различны, на основе НВБР можно создать компактный датчик для измерения воздействия сразу нескольких физических величин. Такие структуры предоставляют гибкость в подстройке длины волны брэгговского резонанса при записи НВБР методом фазовой маски.

В ходе настоящей работы был модернизирован интерферометр Тальбота для возможности записи НВБР. Были записаны НВБР с различными внешними углами наклона, а также получены и проанализированы изображения НВБР с внешними углами наклона $4^{\circ}, 10^{\circ}$ и $20^{\circ}$. На основе полученных данных экспериментально проверена расчетная зависимость внутреннего угла наклона решетки от внешнего угла между штрихами интерференционной картины и поперечным сечением OB.

Настоящая работа выполнена в Университете ИТМО при финансовой поддержке Министерства образования и науки Российской Федерации (Уникальный идентификатор проекта: RFMEFI57816X0202, Соглашение № 14.578.21.0202).

\section{Список литературы}

[1] Hill K.O., Fujii Y., Johnson D.C., Kawasaki B.S. // Appl. Phys. Lett. 1978. V. 32. N 10. P. 647-649.

[2] Hill K.O., Meltz G. // J. Lightwave Technology. 1997. V. 15. N 8. P. $1263-1276$.

[3] Kashyap R. Fiber Bragg gratings, 2nd Edn. Academic Press, 2011.

[4] Othonos A., Kalli K. Fiber Bragg Gratings: fundamentals and applications in telecommunications and sensing // Artech House, 1999.

[5] Meltz G., Morey W.W., Glenn W.H. // Optical fiber Communication Conference, OFC. 90, San Francisco, CA, 1990.

[6] Kashyap R., Wyatt R., Campbell J. // Electronics Lett. 1993. V. 29. N 2. P. $154-156$.

[7] Wagener J.L., Strasser T.A., Pedrazzani J.R., DeMarco J., DiGiovanni D. // Integrated Optics and Optical Fibre Communications, 11th International Conference on, and 23rd European Conference on Optical Communications (Conf. Publ. No.: 448). IET. 1997. V. 5. P. 65-68.

[8] Castro J.M., Geraghty D.F., West B.R., Honkanen S. // Appl. Opt. 2004. V. 43. N 33. P. 6166-6173.

[9] Caucheteur C., Mégret P. // IEEE Photonics Technology Lett. 2005. V. 17. N 12. P. 2703-2705.

[10] Laffont G., Ferdinand P. // Meas. Sci. Technol. 2001. V. 12. N 7. P. 765-770.

[11] Chan C.F., Chen C., Jafari A., Laronche A., Thomson D.J., Albert J. // Appl. Opt. 2007. V. 46. N 7. P. 1142-1149. 
[12] Zhou K., Chen X., Zhang L., Bennion I. // Proc. SPIE. 2005. V. 5855. P. $158-161$.

[13] Zhou K., Chen X., Zhang L., Bennion I. // Measurement Science and Technology. 2006. V. 17. N 5. P. 1140.

[14] Peupelmann J., Krause E., Bandemer A., Schaffer C. // Electron. Lett. 2002. V. 38. N 21. P. 1248-1250.

[15] Bouzid A., Abushagur M.A., El-Sabae A., Azzam R.M.A. // Opt. Commun. 1995. V. 118. N 3-4. P. 329-334.

[16] Westbrook P.S., Strasser T.A., Erdogan T. // Optical Fiber Communication Conference. Optical Society of America. 2000. Paper PD22.

[17] Chen X., Zhou K., Zhang L., Bennion I. // IEEE photonics technology letters. 2006. V. 18. N 24. P. 2596-2598.

[18] Mihailov S.L., Walker R.B., Stocki T.J., Johnson D.C. // Electron. Lett. 2001. V. 37. N 5. P. 284-286.

[19] Yariv A. // IEEE J. Quantum. Electron. 1973. V. 9. N 9. P. 919-933.

[20] Chen X. // Current Developments in Optical Fiber Technology. InTech, 2013.

[21] Gribaev A.I., Pavlishin I.V., Stam A.M., Idrisov R.F., Varzhel S.V., Konnov K.A. // Opt. Quant. Electron. 2016. V. 48. Art. 540. P. 1-7.

[22] Варжель С.В., Мунько А.С., Коннов К.А., Грибаев А.И., Куликов А.В. // Оптический журнал. 2016. Т. 83. № 10. C. $74-78$. 